\title{
O uso de inibidores de apetite por mulheres: um olhar a partir da perspectiva de gênero
}

\author{
The use of apetite inhibitors by women: \\ an insight based on the gender perspective
}

Cristiane Magalhães de Melo ${ }^{1}$

Djenane Ramalho de Oliveira ${ }^{2}$

${ }^{1}$ Secretaria Municipal de Saúde, Prefeitura de Viçosa. Rua Gomes Barbosa 803, Centro. 36570-000 Viçosa MG. cristianeufv@yahoo.com.br ${ }^{2}$ Departamento de Farmácia Social, Faculdade de Farmácia, Universidade Federal de Minhas Gerais.

\begin{abstract}
The scope of this study was to understand the motives that lead adult women to use appetite inhibitors and to establish, from a gender perspective, how these women relate to their own bodies. It was structured around the principles of qualitative research, and the methods of data collection were semi-structured interviews and direct observation. The informants were six women who used appetite inhibitors. The results indicated that images, publicity and social networks contribute significantly to the creation of new standards of physical appearance as well as lifestyles, which establish appearance (a slim body) and a happy marriage as the desired model. The slim body is represented as something able to alter the temperament of the individual, in other words a fat person is an unhappy person and a slim person is a happy person. The study shows that it is in the body per se that the social role destined for women is produced and reproduced.
\end{abstract}

Key words Body, Gender, Appetite suppressants, Femininity
Resumo O presente estudo teve como objetivo compreender os motivos que levam mulheres adultas a utilizar medicamentos inibidores do apetite e verificar, a partir da ótica de gênero, como se estabelece a relação dessas mulheres com seus próprios corpos. Orientado pelos princípios da pesquisa qualitativa, utilizou como técnicas de construção de dados a entrevista semiestruturada e a observação direta. Participaram como informantes do estudo seis mulheres usuárias de anorexígenos. Os resultados apontaram que as imagens, a publicidade e as redes sociais contribuem significativamente para a criação de padrões de aparência física e de "estilos de vida", cujo modelo preconiza a boa aparência (corpo magro) e a felicidade conjugal. O corpo magro é representado como algo capaz de alterar condições, ou seja, pessoa gorda = pessoa infeliz; e pessoa magra = pessoa feliz. $O$ estudo mostra que é no corpo como lócus que o papel socialmente destinado às mulheres será produzido e reproduzido.

Palavras-chave Corpo, Gênero, Anorexígenos, Feminilidade 


\section{Introdução}

A aplicação da categoria gênero em estudos na área da saúde tem sido recente, e durante muito tempo houve uma tendência em considerar tudo que se refere ao corpo como "natural", "a-histórico" e "imutável". No entanto, a partir do final do século XX e do início do XXI, diferentes áreas do conhecimento passaram a discutir a singularidade do corpo e do gênero na cultura brasileira ${ }^{1}$.

A inclusão do gênero proposto fundamentalmente por $S \operatorname{cott}^{2}$ como categoria analítica é fundamental em estudos relacionados à saúde $\mathrm{e}$ ao corpo, uma vez que rejeitar o determinismo biológico e a ideia "naturalizada" da distinção sexual contribui para a compreensão das iniquidades calcadas nas relações hierárquicas de poder. O corpo é, nesse contexto, compreendido como um objeto histórico e cultural e, como tal, um lócus privilegiado do controle social. Ressalta-se, ainda, que as percepções e os conceitos sobre o corpo são construídos e reconstruídos permanentemente no cotidiano dos sujeitos e das coletividades ${ }^{3}$.

Na contemporaneidade, é possível perceber uma grande preocupação por parte dos indivíduos com relação à imagem e à estética. A indústria cultural valoriza o corpo esbelto e esguio, fazendo com que essa formulação seja aceita e difundida amplamente. $\mathrm{O}$ culto à juventude e ao corpo exige dos indivíduos autovigilância e adaptação ${ }^{4}$.

Para as mulheres, a beleza e a juventude tornaram-se um imperativo. Uma qualidade fundamental. Seria esse o caminho para a reprodução social respaldada na promessa da "felicidade". É esse o discurso da indústria cosmética, médica, do esporte, dentre outras: a felicidade está ao alcance de todos, pois a beleza e a juventude estão ao alcance de todos, para tanto podemos lançar mão de produtos e serviços especializados ${ }^{5-7}$.

Os medicamentos situam-se nessa esfera, ou seja, constituem-se um símbolo, algo a ser adquirido/consumido para um fim maior: a saúde, a beleza, o bem-estar físico, mental e comportamental ${ }^{8-13}$. Os anorexígenos, ou moderadores de apetite, podem ser considerados um exemplo de medicamento que simboliza a beleza, nesse caso um corpo magro.

Os anorexígenos ou anoréticos são drogas de alto consumo no Brasil para o tratamento da obesidade. Segundo dados da Secretaria de Vigilância Sanitária do Ministério da Saúde ${ }^{14}$, o consumo brasileiro chega a 23,6 toneladas anuais. Um inquérito realizado na cidade de Belo Horizonte (MG) em 2002 apontou um crescimento no consumo desses medicamentos e ainda que esse consumo ocorre, predominantemente, via produtos manipulados ${ }^{15}$. É importante considerar que essa realidade já havia sido observada em estudos sobre a realidade brasileira, salientando que o consumo se dá principalmente por via lícita através de receita médica ${ }^{16}$.

Estudos realizados em clínicas de emagrecimento em São Paulo (SP) e Recife (PE) nos anos de 1991 e 1992 mostraram que a maioria dos frequentadores não poderia ser classificada como obesa considerando o Índice de Massa Corporal (IMC). Esses estudos identificaram ainda que, em geral, os pacientes tinham pouco conhecimento da medicação da qual faziam uso ${ }^{14}$.

Ao se considerar a questão do gênero no consumo de anorexígenos, um estudo realizado em Belo Horizonte em $2004{ }^{17}$ observou a predominância de consumo por mulheres ( $88 \%)$, na proporção de 10:1.

A sociedade torna-se, cada vez mais, dependente da utilização de fármacos para conseguir a "cura" de determinada enfermidade, cuja existência, muitas vezes, é criada a partir de um processo complexo que envolve a "indústria médica" e seu arsenal farmacêutico que retira das condições de vida os determinantes do adoecer, fazendo com que este recaia sobre o indivíduo e seu corpo $^{11,18,19}$.

A "ideia dominante sobre o "uso de medicamentos" e sobre o "uso racional de medicamentos" não contempla os comportamentos de consumo que são altamente prevalentes na sociedade atual, além de subestimar as constantes deliberações, ajustes e alterações exercitadas por pacientes no dia a dia de uso de medicamentos. Ao considerar a subjetividade dos atores, situada em um contexto social, podemos apreciar racionalidades que divergem das normas científicas objetivas tradicionais ${ }^{20}$.

Nesse contexto, o objetivo do presente estudo foi compreender os motivos que levam mulheres adultas a utilizar medicamentos inibidores do apetite e o que há por trás do desejo de se ter um corpo magro. Objetivou-se, também, compreender as concepções de corpo feminino em situações concretas, mais especificamente nas situações de mulheres que utilizam medicamentos anorexígenos.

\section{Métodos}

Neste estudo, foi utilizada a abordagem qualitativa. Nessa perspectiva, a realidade social é múl- 
tipla, não quantificável e subjetiva, ou seja, está subordinada ao olhar e à experiência das pessoas que a vivenciam ${ }^{21}$. Os dados utilizados foram construídos a partir de pesquisa empírica e constituíram-se numa tentativa de ilustrar como diferentes mulheres se relacionam com o próprio corpo e a percepção dessas mulheres sobre o uso de medicamentos anorexígenos.

O estudo foi realizado no período de fevereiro a agosto de 2007. As técnicas de campo utilizadas foram a entrevista semiestruturada e a observação direta assistemática. Foi utilizado também, como técnica auxiliar, o diário de campo. Essas técnicas foram escolhidas por permitirem a interação entre pesquisador e informante e a construção de dados ricos para a pesquisa qualitativa ${ }^{21,22}$.

Para as entrevistas, foi elaborado um roteiro com perguntas a fim de subsidiar as discussões sobre o tema abordado. Cada informante foi entrevistada uma única vez, e as entrevistas tiveram duração média de aproximadamente sessenta minutos. As entrevistas foram realizadas após a assinatura do termo de consentimento, de acordo com a Resolução no 196/96 do Conselho Nacional de Saúde, na própria residência das informantes. Todas as entrevistas foram gravadas em fita cassete e depois transcritas textualmente por uma das pesquisadoras.

A observação direta assistemática foi o método de observação direta utilizado. Discursos de mulheres e conversas entre mulheres na forma em que eles emergiram nas situações concretas foram privilegiados. Assim, não foram estabelecidos locais nem horários para a realização da observação. Foram feitas observações em locais de trabalho e lazer, ou seja, em locais em que ocorrem naturalmente conversas entre mulheres e em que emergem discussões sobre corpo, uso de medicamentos e estética.

Participaram como informantes do estudo seis mulheres que estavam usando ou que haviam utilizado medicamentos anorexígenos. As mulheres caracterizam-se por pertencerem a estratos sociais médios e por possuírem curso superior. Para a seleção das participantes, foi utilizada a técnica do Snowball, em que a primeira mulher indicou a próxima mulher a ser convidada a participar do estudo, e assim por diante. As informações provenientes das entrevistas atingiram a saturação com a sexta entrevista, o que significa que as informações se repetiram, validando os dados obtidos nas entrevistas anteriores.

O tratamento e a análise do material coletado durante o trabalho foram subdivididos em três etapas: ordenação, classificação e análise. Buscou- se estabelecer o movimento entre o discurso em sua totalidade, as partes desse discurso e o retorno ao todo ${ }^{23,24}$. Assim, a partir da análise do todo, cada parte foi focalizada separadamente visando à compreensão dos sentimentos, crenças, comportamentos e significados da experiência presente nos discursos de cada uma das informantes da pesquisa. Buscou-se ainda encontrar expressões e palavras que expressassem sentimentos e características comuns. Essas expressões foram agrupadas de modo a compor as categorias que serão apresentadas e discutidas a seguir.

\section{Resultados e discussão}

\section{Medicamento como símbolo}

Um dos sentidos do medicamento difundido socialmente está relacionado ao de uma mercadoria que, ao ser consumida, é capaz de satisfazer uma necessidade e de conduzir o paciente de um estado "ruim" para um estado "bom", de um estado de não saúde, de insatisfação, para um estado de saúde/satisfação $0^{8,9,11,18-20}$.

É importante ressaltar que quando consideramos a função simbólica do medicamento, estamos focando nos significados atribuídos a este produto/mercadoria, o que provavelmente irá variar conforme a situação social do sujeito. Assim, o medicamento pode ter um significado para o prescritor e um significado diferente para o paciente, ou o usuário do medicamento. Neste estudo, abordamos o significado do medicamento na perspectiva do paciente, e mais especificamente do ponto de vista de mulheres usuárias de medicamentos anorexígenos.

Durante todo o trabalho de campo, foi possível verificar que o medicamento para emagrecer está sempre associado à ideia da magia, do "milagre", sendo algo necessário e fundamental na busca pelo corpo magro e aceito socialmente. Ou seja, constitui-se em ponto de apoio, uma "bengala", que auxilia ou que conduz ao objetivo final, que é o emagrecimento.

Eu sentia nele... como se fala... uma bengala! Eu emagrecia porque eu tava tomando remédio. Só "deu" tá tomando eu emagrecia. Sem ele o regime não funcionava. É uma droga, né?

Alguns autores analisaram especificamente as funções e os significados de certos medicamentos e prescrições como amuletos ou talismãs dos dias atuais ${ }^{25-27}$. Neste estudo, as informantes apresentam o medicamento como "bengala", mas apontam a participação da pessoa no processo 
de emagrecimento. As mulheres colocam o medicamento como um estímulo ao emagrecimento que foi rápido, mas que dependeu do esforço, da participação delas.

Parece um milagre. Você começa a tomar e ele começa a fazer efeito. Na hora a gente fica muito feliz. Emagrecer assim num passe de mágica. Mas também, quando você começa a tomar esse medicamento, além dele te tirar o apetite, você também vira e fala assim: "Não, eu não vou comer muito não porque eu tô tomando remédio." Entendeu? Mesmo se te dá fome, cê fala assim: vou comer menos, porque eu tô tomando remédio. E também, quando você come muito te dá dor de barriga. Então acaba que você mesmo não consegue comer.

Os discursos apontam sempre para a importância do medicamento no processo de emagrecimento e para a necessidade da participação da pessoa - do autocontrole/da vigia constante. $\mathrm{Ou}$ seja, há uma necessidade de se vigiar constantemente para não cometer abusos, pois esses abusos serão "punidos". É o que ficou evidente a partir da leitura da fala anterior, "quando você come muito te dá dor de barriga", assim a pessoa não pode comer muito.

A função simbólica do medicamento está associada ao significado que ele tem para a paciente, ou para um grupo de pacientes. Neste estudo, o medicamento anorexígeno é experimentado subjetivamente como uma bengala que auxilia a mulher no processo de emagrecimento.

O estudo de Shoemaker e Ramalho de Olivei$\mathrm{ra}^{28}$ também revelou o simbolismo e os significados associados ao uso crônico de medicamentos, na perspectiva dos usuários de medicamentos. As autoras expressaram a importância de se compreenderem esses significados no cuidado ao paciente quando temos como objetivo atender às suas necessidades relacionadas à farmacoterapia. Os significados atribuídos aos medicamentos possivelmente influenciarão o comportamento e o processo de tomada de decisão do paciente com relação a sua saúde e ao seu tratamento.

\section{$\mathrm{O}$ medicamento e as redes sociais}

A análise da experiência das mulheres permitiu evidenciar a importância que as redes sociais assumem quando tratamos de medicamentos anorexígenos. E nesse sentido podemos dizer que as relações simbólicas mantidas com o medicamento perpassam não só pelo paciente, mas, como afirmou Lefèvre ${ }^{8}$, por toda uma categoria de agentes sociais, entre eles a família, os vizinhos, o farmacêutico e o médico prescritor. Como alguns estudos sugerem, fatores como a estrutura fami$\operatorname{liar}^{29} \mathrm{e}$ a percepção das redes sociais ${ }^{30}$ são fatores que influenciam significativamente a decisão de usar ou não usar um medicamento.

É interessante observar a fala de uma das mulheres que buscou informações com profissionais a respeito do uso do fármaco. Embora esses profissionais tenham contraindicado o uso, a troca de experiências com familiares usuários foi mais importante na escolha e na opção pelo uso do medicamento.

Eu cheguei a perguntar a alguns profissionais. Todos que eu perguntei me contraindicaram. Mas eu conhecia os efeitos através da minha cunhada. Eu não conhecia ela antes, mas ela me mostrou as fotos, enorme! Quando eu a conheci, ela tava magra. Então, eu conhecia o efeito. O efeito do medicamento, entendeu? Então eu queria o efeito pra mim também. Independente de qualquer efeito colateral.

Situação semelhante foi possível verificar em outro discurso. A informante informa que o namorado e a cunhada estavam tomando medicamento pra emagrecer e foi com eles que ela obteve informações sobre o fármaco e até mesmo o próprio medicamento para o uso:

Eu queria emagrecer, e minha cunhada e meu namorado tavam tomando esse remédio, aí eu achei que seria interessante eu experimentar pra ver no que dava. Eu peguei o mesmo que foi pro meu namorado. Porque ele usou e não tava gostando porque tava dando uns efeitos colaterais, aí eu fui e comecei a usar.

Os discursos aqui apresentados nos remetem a uma discussão sobre a automedicação. Como demonstrado e discutido por diversos autores $^{31-34}$, a automedicação é uma forma importante de autocuidado, de resposta a sintomas, e a forma mais prevalente de cuidado à saúde.

Neste estudo, a automedicação é uma resposta importante das mulheres à insatisfação com seus corpos. Também é evidenciado que a opinião de parentes e a experiência vivenciada por familiares, amigos ou por outras pessoas do convívio social é definitiva na escolha do método para emagrecer. Um dos discursos revela ainda que o próprio medicamento - alvo de controle pelas autoridades sanitárias nos estabelecimentos comerciais - tem sua utilização banalizada quando, por meio da automedicação, é repassado de pessoa a pessoa.

Ressalta-se que, embora pareça existir certo conhecimento sobre os riscos envolvidos na automedicação e no uso abusivo dos medicamentos para emagrecer, as mulheres se submetem ao 
risco. Tal atitude pode estar relacionada ao que Huertas e Campomar ${ }^{35}$ denominaram componente cognitivo da atitude do consumidor perante os medicamentos anorexígenos. Segundo os autores, essa categoria de medicamento, embora considerada não saudável, duvidosa e prejudicial, são também consideradas necessárias, convenientes e efetivas, sendo seus benefícios emocionais avaliados positivamente, fazendo com que as mulheres se sintam animadas, confiantes, motivadas, esperançosas e reconhecidas.

\section{Beleza, família e papéis sociais}

Como você se sente como mulher? Na sua opinião, como o corpo feminino deve ser? Alguém já falou que você precisava emagrecer?

Estas perguntas foram feitas às informantes durante as entrevistas e permitiu evidenciar questões relacionadas às expectativas sociais sobre os papéis a serem desempenhados por essas mulheres. Para as mulheres participantes neste estudo, o desempenho de certos papéis sociais seria a garantia do sucesso profissional e da felicidade. A beleza física, ligada à noção de corpo magro, aparece nos discursos como um imperativo na conquista e na manutenção do relacionamento conjugal. As mulheres apontam também a importância de "estar bem comigo mesma", e este "estar bem”, como as próprias palavras nos remetem a pensar, consiste em um estado que depende, em grande parte, da satisfação com a aparência física.

Quando eu conheci [o namorado], eu tava com o menor peso que eu tinha atingido: 49 quilos. Ai a gente começou a namorar. Deu certo, né? Tipo assim: atingi todos os meus objetivos, né? [risos], mas não que eu pensasse em emagrecer pra arrumar namorado, primeiro eu queria ficar bem comigo mesma, porque eu me achava feia, horrivel, né?

O corpo magro é apresentado nos discursos como algo capaz de alterar condições, ou seja, uma pessoa gorda = pessoa infeliz; e pessoa magra = pessoa feliz. $\mathrm{O}$ corpo é representado pelas mulheres entrevistadas como objeto a ser moldado e utilizado na conquista da felicidade e da ascensão social - casamento e trabalho. É no corpo como lócus que o papel destinado às mulheres no que tange à constituição da família e geração de filhos será produzido e reproduzido. O corpo feminino é representado socialmente como um objeto necessário à conquista da "felicidade".

Cê tem que se adequar com o povo que tá do seu lado, sim. Só que eu acho que com relação a corpo, eu acho que você tem que tá bem com você. A gente tem que tá feliz com a gente mesmo.
Em todos os discursos, a expressão "estar bem consigo mesma" apareceu e sempre associada à ideia do corpo magro. Vale a pena considerar que as mulheres parecem utilizar esta expressão como uma justificativa para a busca do corpo magro, ou seja, como uma defesa à ideia de estar se submetendo aos apelos midiáticos ou pela necessidade de atender a uma demanda social querem emagrecer porque querem estar bem consigo mesmas e não devido ao modelo de feminilidade incessantemente veiculado na mídia.

A divisão binária do mundo entre masculino e feminino determina modelos de corpo, valores e comportamentos a serem desempenhados por homens e mulheres. Nesse contexto, o perfil de mulher tende à homogeneização - mulheres magras, bem-sucedidas, felizes (casadas e com filhos), acima de tudo, mulheres "bem com elas mesmas".

As representações sobre mulheres ligadas a atributos como passividade, sensualidade, incapacidade intelectual e, sobretudo, dependência de seu corpo e sexo vêm sendo reafirmadas cotidianamente por meio da mídia em geral - novelas, propaganda, revistas, Internet, por exemplo. Nesse contexto, Santos e Silva ${ }^{36}$ apontam a participação da mídia na produção e na reprodução de formas simbólicas - entre elas, as relações entre gêneros.

Swain ${ }^{7}$ considera que, apesar das transformações evidenciadas ao longo dos anos no plano jurídico graças aos movimentos feministas, essas transformações não atingiram as representações de gênero que definem os modelos de ser.

A instituição de normas e modelos corpóreos compartilhados e reificados por meio das representações sociais definem os campos e os limites do aceitável e do inaceitável. O casamento, a maternidade, a heterossexualidade tornam-se atributos aceitáveis para a mulher e devem ser buscados por meio principalmente do corpo (moldado para tal). Nesse sentido, Goldenberg ${ }^{1}$ lembra que a busca pelo corpo magro correspondente ao ideal de delicadeza e submissão das mulheres em relação aos homens, e pela força física, tamanho do tórax e pênis que corresponde ao ideal de virilidade e força para os homens, tem levado, cada vez mais, jovens brasileiros a distúrbios como anorexia e bulimia, bem como a uso abusivo de esteroides anabolizantes.

A partir do trabalho de campo, verificamos que a família das informantes e, principalmente, os homens têm grande participação na reprodução do modo de se pensar o "ser mulher". Durante as entrevistas e quando indagadas se al- 
guém já havia dito que elas precisavam emagrecer, as informantes foram unânimes em apontar os irmãos, o marido e o pai.

Meu irmão me estressava. Meu irmão estressa minha cunhada, entendeu? Fica te chamando de gorda, de baleia! Gente, é tudo que você menos quer ouvir! Minha mãe fala também. Meu avô falava que eu tava ficando igual minha avó. Minha avó é desse tamanho, né? Meu marido... ele cobra: "Tá ficando barriguda!"

A cobrança da família com relação à aparência física parece estar associada à expectativa da família no que diz respeito ao desempenho dos papéis e aos atributos historicamente associados às mulheres. Podemos destacar aqui a questão do casamento e da maternidade como algo historicamente considerado como inerente à condição feminina. Mas como desempenhar tais papéis se não se tem a arma da aparência física? $\mathrm{O}$ discurso abaixo evidencia a preocupação da família com relação a esta questão. Refere-se ao discurso de uma mãe (usuária de anorexígeno) sobre a filha que não se casou:

Aparência é tudo hoje. A minha filha me deixa preocupada porque ela não casou. Ela é uma moça solteira. Hoje talvez eu possa dar o luxo de falar que não preciso disso porque eu já tenho uma família constituída. Mas ela ainda não tem. Um rapaz não olha para uma moça desse jeito, 82 quilos! Isto é natural. É do ser humano. Cê olha pro que é bonito! Pras meninas que eu falo muito: o homem não precisa ser bonito. Meu marido não é bonito. Tem que ser trabalhador.

O discurso evidencia também a questão da divisão social do trabalho entre os gêneros. Enquanto ao homem é atribuído o dever de manutenção financeira da família, à mulher é destinada a tarefa da reprodução social por meio do casamento e da maternidade. A naturalização dos papéis masculinos e femininos também pode ser claramente observada.

Quando indagadas a respeito do que sentiam quando alguém insinuava que elas precisavam emagrecer, elas revelaram em seus discursos sentimentos de tristeza, baixa autoestima e até mesmo revolta.

Ai! É tudo que você menos quer ouvir. Você sabe que tá gorda. Não precisa te falar que você tá uma baleia, não. Cê tem espelho, né? Meu pai de vez em quando fala com minha tia e tal... Vai direto no ponto fraco dela, né? Magoa muito. É uma coisa simples, né? Pra quem não tá sentindo na pele, não tem nada a ver, mas pra quem tá sentindo... tá tentando emagrecer e não consegue... se olha no espelho e se sente a última das pessoas... É tudo que ela menos quer ouvir - que tá gorda, feia. Não é? É muito ruim!

Embora carregados de sofrimento, os discursos demonstram que as mulheres assumem a magreza como padrão de beleza generalizável ser gorda é ser feia. Apesar de afirmarem se sentir mal quando alguém insinuava que elas precisavam emagrecer, em outros momentos da entrevista assumem desempenhar o mesmo padrão de comportamento com outras pessoas. Quando as mulheres assumem desempenhar o mesmo padrão de comportamento que os companheiros, irmãos ou pais com relação à cobrança pelo corpo magro (padrão), afirmam que isso é importante, principalmente no caso das mulheres, o que permite identificar um forte viés de gênero na reprodução social de valores sociais e comportamentos.

A busca pelo padrão de corpo difundido pela mídia aparece no discurso das mulheres muitas vezes revestido de simplicidade, isto é, nas falas dessas mulheres é apresentado apenas o desejo de se sentirem "bem na roupa”. Entretanto, há de se considerar o que há por trás do desejo de se sentir bem na roupa, uma vez que a moda é pensada e carrega consigo toda uma concepção de corpo que é característica de uma época. As roupas, a modelagem e os tamanhos são elaborados a partir de um padrão socialmente difundido.

No discurso a seguir, podemos perceber certa resistência em assumir o desejo de se ter um corpo "padrão". A informante afirma não querer ser magra, apenas querer "estar bem na roupa que ela gosta”. O discurso é contraditório à medida que, como já foi indicado, a moda atual é construída e elaborada a partir de um discurso que preconiza a magreza.

É vestir uma roupa e tá bem lá dentro. Não ter que ficar usando outros tipos de roupas só porque o meu corpo não tá legal. Pra mim esse é o tipo de corpo ideal. Eu não quero ser magra. Eu só quero ficar bem na roupa que eu vou pôr. Eu não tenho esse padrão de beleza, magro, não. Não acho bonito, não.

Em outra fala, o discurso da felicidade vinculada ao corpo magro, a moda e até o valor pago pelas roupas são apresentados. A informante afirma que antes de tomar o medicamento e emagrecer ela não era feliz, pois não se adequava. Ou seja, estava fora do padrão e por isso pagava um alto preço.

Mas eu não era feliz, porque qualquer roupa que você vai vestir fica horrivel! Nada te serve! É uma luta pra você encontrar/comprar roupa que te serve. Então pra mim é mais caro. Você não 
encontra roupa pra pessoa um pouco mais gordinha, cê não encontra roupa um pouco mais larguinha. É só roupa justa. Então cê vai comprar roupa e você chora! Volta pra casa chorando porque você não encontra nada. Entendeu? Sua autoestima fica um lixo! Nossa, você se acha a pessoa mais feia do mundo!

A análise das falas evidencia o que vem sendo discutido neste e em outros estudos que abordam as relações de gênero e a situação das mulheres ${ }^{36,37}$. Embora as conquistas dos movimentos feministas sejam uma realidade, as representações do que é feminino e masculino mantêm-se historicamente. Às mulheres cabem os atributos de sensibilidade, destreza no cuidado com os filhos e a família, além de serem também lindas e absolutamente jovens, bem-humoradas e sucedidas tanto no trabalho quanto no cuidado com o lar.

Com relação à moda, pode-se dizer que ela é elaborada por poucos para poucos, excluindo corpos e modelando aqueles para os quais ela foi pensada. E como diz Barthes ${ }^{38}$, a moda cria corpos, alonga, incha, reduz, aumenta, diminui, afina, e por estes artifícios a moda afirma que pode submeter não importa que acontecimento (não importa o corpo real) à estrutura que ela postula.

\section{A relação médico-paciente}

A figura do médico assume importância para essas mulheres como via ou mecanismo de acesso ao medicamento, e a informação sobre o profissional aparece sempre associada à figura de uma pessoa conhecida - parentes ou amigos que já fizeram uso dos serviços prestados pelo referido médico.

Eu fiquei sabendo do médico através do sogro do meu irmão e da minha cunhada, que já fazia tratamento com esse mesmo médico há muito tempo, e ai marquei uma consulta e fui. Eu fui lá uma vez só. Não precisei voltar.

Esses profissionais, acompanhando a tendência do inquérito realizado em Belo Horizonte em $2004^{39}$, especializam-se na prescrição de fórmulas de emagrecimento, tornando-se conhecidos entre a população usuária desses fármacos.

Ele é cardiologista, mas ele só receita fórmula pra emagrecimento. Todo mundo que procura a clínica dele vai procurando emagrecer. O objetivo é emagrecer. Nenhuma pessoa que vai lá volta pra casa sem medicamento. Ninguém. Ele é conhecido, a fama dele é por esse tratamento, entendeu? Ele é sinônimo disso, sabe: de anorexígeno.

Os discursos demonstram também a possibilidade da quebra da relação médico-paciente, caso seja negada a prescrição do fármaco, e a "corrida" a que os pacientes se submetem na busca pela "pilulazinha milagrosa”. Resultados semelhantes são relatados por Whyte et al. ${ }^{10}$ em seu estudo sobre mulheres usuárias de benzodiazepínicos.

Não adianta o médico. Porque se a gente for lá ele vai te dar o remédio! Mesmo porque você tá buscando! Ele vai falar, não? Você é maior de idade, sabe o que tá fazendo. Ele explica, mas te dá. Eles não negam. Eu nunca vi nenhum negar. Ele sabe que se não der, outro dá.

A relação entre médico e paciente algumas vezes não se restringia à busca e ao fornecimento da fórmula para emagrecimento. Em um dos relatos, foi possível identificar o sofrimento da informante quando percebe a pressão exercida pelo profissional de saúde ou pelos programas de emagrecimento para com as pacientes.

Tomei uma birra de nutricionista porque eu fui em todas, né? E eu não conseguia comer aquilo que elas punham pra mim. Porque eu tava mais nova, tinha mais vontade de comer. Você tem que ir lá e pesar tanto a menos, era muita pressão. Aí eu sumia de lá. Mudava de médico.

Em outro momento, a informante relata um fato que aconteceu com ela quando buscou uma clínica para tratamento da "compulsão pra comer":

Eu fui até numa clínica. Num médico que eu não lembro o nome. Eu pesava na época 89 quilos, por aí. Ele leva a gente pra uma salinha e fala: "Suas porcas, cês enchem o espaço, cês não tão comendo por baixo, comem por cima”. Eu só não assustei muito porque uma amiga tinha avisado que tinha um teatro. Mas tinha umas pessoas que ficavam em estado de choque. As mulheres ficavam com o olho desse tamanho! Cê paga pra ouvir desaforo.

Continuando, a informante assume já ter passado por situações parecidas em outras ocasiões e aponta o medicamento como alternativa para não ter que passar por constrangimentos:

Eu já paguei pra ouvir cada coisa de médico! "Cês pensa que a gente estuda dez anos pra fazer regime procês? Por que cês não fecha a boca?” Aí a gente quer o quê? Remédio, né?

O medicamento aparece como uma alternativa para o emagrecimento. É o "milagre" tão esperado sintetizado em uma pílula. Entretanto, ao mesmo tempo que essa mercadoria aparentemente "liberta" a paciente da permanente pressão exercida por determinados profissionais ou por determinados programas de emagrecimento, a submete a outro tipo de dependência: a do poder exercido pelo médico prescritor. Portanto, a experiência dessas mulheres reflete a ambigui- 
dade de significados do medicamento anorexígeno. Whyte et al..$^{10}$ discutem o papel ambíguo que os medicamentos ansiolíticos, os benzodiazepínicos, desempenham na vida de mulheres holandesas. Por um lado, esses medicamentos dão às mulheres uma sensação de estar no controle de suas vidas, uma vez que diminuem o estresse provocado pela vida cotidiana; por outro, com o uso continuado dos benzodiazepínicos, as mulheres passam a se sentir controladas pelo medicamento, uma vez que passam a desenvolver tolerância a ele e se tornam dependentes do prescritor para garantirem acesso ao produto. Para as usuárias de benzodiazepínicos, assim como para as usuárias de anorexígenos deste estudo, o uso do medicamento significa, ao mesmo tempo, ganho e perda de controle.

\section{Conclusão}

A realização deste estudo contribuiu para a compreensão de como o consumo de substâncias psicotrópicas anorexígenas está associado a questões de ordem social e envolve entre outros fatores, a estética e o modelo de feminilidade socialmente construído e esperado.

O percurso teórico-metodológico e a opção em se trabalhar com um grupo de mulheres permitiram evidenciar que o consumo de tais substâncias pode ser associado à grande preocupação por parte dos indivíduos com relação à imagem corporal e que essa preocupação está diretamente relacionada ao momento sócio-histórico por que passam as sociedades ocidentais.

As imagens e a publicidade contribuem, assim, significativamente para a criação de novos padrões de aparência física e de "estilos de vida", cujo modelo preconiza a boa aparência (corpo magro) e a felicidade conjugal.

Para as mulheres, a beleza tornou-se um imperativo, e o corpo (de ordem da natureza), algo que deve ser "dominado/domesticado", a fim de se conquistar o papel social destinado às mulhe- res e com ele a "felicidade". Esta afirmativa pôde ser comprovada por meio da pesquisa empírica. A análise das entrevistas e a observação direta permitiram compreender como as mulheres constroem os significados atribuídos ao corpo e aos medicamentos para emagrecer.

Nesse contexto, o medicamento assumiu, como afirma Lefèvre", o sentido de coisa "benéfica" e apareceu entre aquele grupo de mulheres como solução para uma situação ou estado maléfico/indesejado prévio. O medicamento foi apresentado como uma mercadoria indispensável na busca pelo ideal - no caso, o corpo magro. $\mathrm{O}$ corpo, por sua vez, foi representado como algo a ser moldado, como um objeto necessário à conquista da "felicidade".

É interessante notar, mais uma vez, que a questão das relações de gênero esteve presente em todas as discussões sobre corpo e beleza, e que essas discussões estiveram sempre vinculadas à noção de corpo magro. A vaidade seria assim um atributo feminino que justificaria o uso de medicamentos, bem como outros procedimentos com finalidade estética por mulheres.

Cabe aqui salientar a importância deste trabalho do ponto de vista das ações de educação para a saúde. É sabido que o uso irracional de anorexígenos implica um grave problema de saúde pública, visto que estudos recentes têm evidenciado o aumento considerável do consumo desse tipo de substância principalmente entre mulheres.

Vale ressaltar, ainda, a importância de estudos como este na formação de profissionais que atuam na área da saúde. Esses profissionais devem estar atentos às questões subjetivas associadas ao uso de medicamentos e às discussões que envolvem o corpo, a saúde e o gênero.

Nesse sentido, entende-se que as ações e os programas educativos devem considerar os múltiplos fatores que estão associados ao ideal de corpo magro - as imagens e representações do corpo, as relações interpessoais, familiares e de gênero e a ideia socialmente construída e difundida sobre feminilidade. 


\section{Colaboradores}

CM Melo e D Ramalho de Oliveira participaram igualmente de todas as etapas da elaboração do artigo.

\section{Referências}

1. Goldenberg M. Gênero e corpo na cultura brasileira. Psicol Clin 2005; 17(2):65-80.

2. Scott J. Gênero: uma categoria útil de análise histórica. Educação e Realidade 1991; 16(2):5-22.

3. Bordo SR. O corpo e a reprodução da feminilidade: uma apropriação feminista de Foucault. In: Jaggarn AME, Bordo SR, organizadores. Gênero, corpo, conhecimento. Rio de Janeiro: Rosa dos Tempos; 1997.

4. Matos AA. Representações sociais do corpo na revista Trip para mulher [dissertação]. Viçosa: Departamento de Economia Doméstica, Universidade Federal de Viçosa; 2003.

5. Jameson F. Pós-modernismo: a lógica cultural do capitalismo tardio. São Paulo: Ática; 1996.

6. Silva AM. Elementos para compreender a modernidade do corpo numa sociedade Racional. Cadernos Cedes 1999; 48(19):7-29.

7. Swain TN. Feminismo e representações sociais: a invenção das mulheres das revistas "femininas". História: questões e debates 2001; 34:11-44.

8. Lefèvre F. O medicamento como mercadoria simbólica. São Paulo: Cortez; 1991.

9. Kramer PD. Listening to Prozac: The Landmark Book About Antidepressants and the Remaking of the Self. New York: Penguim Books; 1997.

10. Whyte SR, Van Der Geest S, Hardon A. Social lives of medicines. Cambridge: Cambridge University Press; 2002.

11. Elliott C. Better than well: American medicine meets the American dream. New York: W.W. Norton \& Company; 2003.

12. Willians SJ, Seale C, Boden S, Lowe P, Steinberg DL. Medicalization and beyond: the social construction of insomnia and snoring in the news. Health 2008; 12(2):251-268.

13. Willians SJ, Seale C, Boden S, Lowe P, Steinberg DL. Waking up to sleepiness: Modafinil, the media and the pharmaceuticalisation of everyday/night life. Sociology of Health and Illness 2008; 30(6):839-855.

14. Brasil. Ministério da Saúde. Secretaria de Vigilância Sanitária. Parecer e recomendações do grupo de estudos assessor da SVS/MS sobre medicamentos anorexígenos. São Paulo: Ministério da Saúde; 1993.

15. Faria MPS, Guerra Júnior AA. Estudo sobre consumo de psicotrópicos anorexígenos em Belo Horizonte $(M G)$ [monografia]. Belo Horizonte: Centro Universitário Newton Paiva; 2002.

16. Nappo SA, Oliveira EM, Morosini S. A prescrição por médicos brasileiros de fórmulas magistrais para emagrecer: uma duvidosa prática para a saúde dos pacientes. Arq Bras Med 1994; 68:15-20.

17. Carneiro MFG, Guerra Júnior AA, Acurcio FA. Prescrição, dispensação e regulação do consumo de psicotrópicos anorexígenos em Belo Horizonte, Minas Gerais, Brasil. Cad Saude Publica 2008; 24(8):1763-1772.

18. Elliott C. A world of our own making: medical enhancement and the pursuit of happiness, dissent, Summer. New York: New York University Press; 2004.

19. Elliott C, Chambers T. Prozac as a way of life. Chapel Hill, NC: University of North Carolina Press; 2004. 
20. Cohen D, McCubbin M, Collin J, Perodeau G. Medications as social phenomena. Health 2001; 5(4): 441-469.

21. Minayo MCS. O desafio do conhecimento: pesquisa qualitativa em saúde. $8^{\text {a }}$ ed. São Paulo: Hucitec; Rio de Janeiro: Abrasco; 2004.

22. Becker H. Problemas de inferência e prova na observação participante. In: Becker $\mathrm{H}$, organizador. Métodos de pesquisa em ciências sociais. São Paulo: Hucitec; 1994. p. 47-64.

23. Dahlberg K, Nystrom M, Drew N. Reflective lifeworld research. Lund: Studentlitteratur; 2001.

24. Ramalho de Oliveira D. Pharmaceutical care uncovered: an ethnographic study of pharmaceutical car practice [tese]. Minneapolis: Graduate School, University of Minnesota; 2003.

25. Sands WL. The tranquilizer tablet: talisman for the 1960s. Psychiatric Quarterly 1965; 39:722-726.

26. Rome HP. Personal reflections: the RX as talisman. Psychiatric Annals 1986; 16:566.

27. Olson JA. Vitamins: the tortuous path from needs to fantasies. Journal of Nutrition 1994; 124 (Suppl.): S1771-S1776.

28. Shoemaker SJ, Ramalho de Oliveira D. Understanding the meaning of medications for patients: the medication experience. Pharm World Sci 2008; 30:8691

29. Mishara B. L'écologie familiale et la consommation de medicaménts chez les personnes âgées (Family ecology and the consumption of medications by elderly persons). Santé Mentale au Québec 1997; 22:200-215.

30. Perodeau G, Gaulbaud du Fort G. Psychotropic drug use and the relation between social support, life events and mental health in the elderly. Journal of Applied Gerontology 2000; 19:23-41.

31. Levin LS, Beske F, Fry Jr. Self-medication in Europe: report on a study of the role of non-prescription medicines. Copenhagen: World Health Organization Regional Office for Europe; 1988.
32. Barros JAC. Propaganda de medicamentos: atentado à saúde? São Paulo: Hucitec/Sobravime; 1995.

33. Coulter A, Parsons S, Askham J. Where are the patients in decision-making about their own care? Policy brief. Copenhagen, Denmark: World Health Organization, on the behalf of The European Observatory on Health Systems and Policies; 2008.

34. Aquino DS, Barros JAC, Silva MDP. A automedicação e os acadêmicos da área de saúde. Cien Saude Colet 2010; 15(5):2533-2538.

35. Huertas MKZ, Campomar MC. Apelos racionais e emocionais na propaganda de medicamentos de prescrição: estudo de um remédio para emagrecer. Cien Saude Colet 2008; 13(Supl.):651-662.

36. Santos DB, Silva RC. Sexualidade e normas de gênero em revistas para adolescentes brasileiros. Saúde e Soc 2008; 17(2):22-34.

37. Ferreira FR. A produção de sentidos sobre a imagem do corpo. Interface - Comunic, Saúde, Educ 2008; 12(26):471-483.

38. Barthes R. Système de la mode. Paris: Seuil; 1981.

39. Carneiro MFG, Acurcio FA, Guerra Júnior AA. Avaliação da prescrição e dispensação de psicotrópicos anorexígenos em Belo Horizonte [monografia]. Belo Horizonte: Faculdade de Farmácia, Universidade Federal de Minas Gerais; 2005.

Artigo apresentado em 07/12/2009

Aprovado em 15/02/2010

Versão final apresentada em 10/03/2010 